IL. Jahres-Versammlung der Schweizerischen Gesellschaft für Dermatologie und Venereologie 25./26. November 1967 in Basel

Dermatologica, 1968;137:281

\title{
Hypersexualität, Antiandrogene und Hodenfunktion
}

F.

Ott

Aus der Dermatologischen Universitätsklinik Zürich (Dir.: Prof. Dr. H. Storck)

Adresse des Autors: Dr. F. Ott, Dermatologische Universitätsklinik, CH-8000 Zürich (Schweiz)

Zusammenfassung

Die Untersuchungsbefunde bei einer Behandlung mit Cyproteron-Azetat werden dargestellt. Bei dieser Substanz handelt es sich um einen peripher wirkenden Testosteron-Antagonisten. Der behandelte Patient war wegen seinen sexuellen Triebstörungen straffällig ge-worden. Unter der Behandlung mit Cyproteron-Azetat verschwand die Libido und die Potenz war stark eingeschränkt. Nach ówöchiger Behandlung war die vorher normale Spermiogenese weitgehend auf-gehoben. Nach 5 1 12 Monaten war dieser Befund unverändert. Die Ho-denbiopsie zeigte beidseits eine fast vollständige Blockierung der Spermiogenese. Zeichen einer Feminisierung konnten keine festge-stellt werden.

In extenso publ.: Praxis 7: 218-220 (1968). 